Provided for non-commercial research and education use. Not for reproduction, distribution or commercial use.

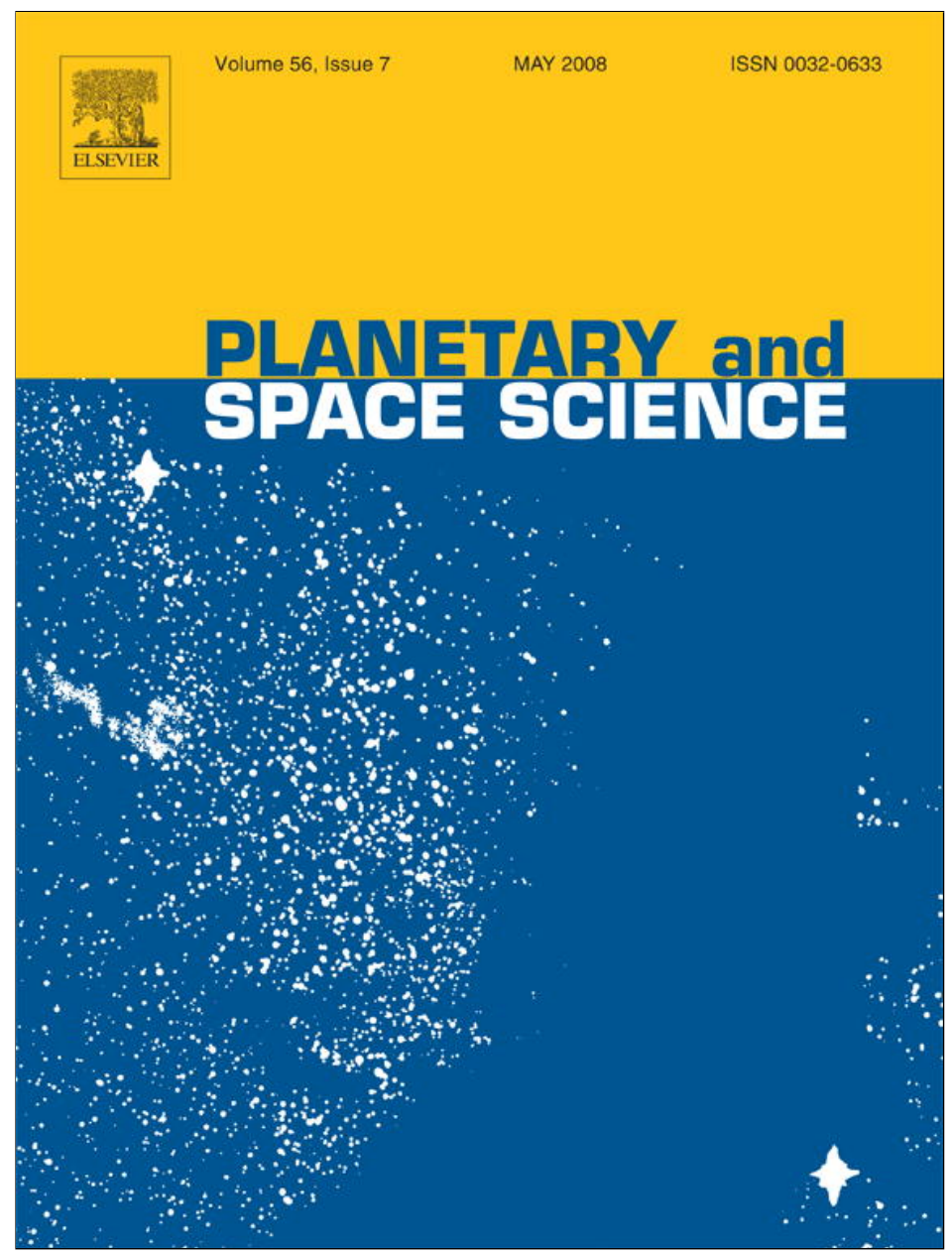

This article appeared in a journal published by Elsevier. The attached copy is furnished to the author for internal non-commercial research and education use, including for instruction at the authors institution and sharing with colleagues.

Other uses, including reproduction and distribution, or selling or licensing copies, or posting to personal, institutional or third party websites are prohibited.

In most cases authors are permitted to post their version of the article (e.g. in Word or Tex form) to their personal website or institutional repository. Authors requiring further information regarding Elsevier's archiving and manuscript policies are encouraged to visit:

http://www.elsevier.com/copyright 


\title{
Mineralogical alteration of artificial meteorites during atmospheric entry. The STONE-5 experiment
}

\author{
Franz Brandstätter ${ }^{\mathrm{a}, *}$, André Brack ${ }^{\mathrm{b}}$, Pietro Baglioni ${ }^{\mathrm{c}}$, Charles S. Cockell ${ }^{\mathrm{d}}$, René Demets ${ }^{\mathrm{c}}$, \\ Howell G.M. Edwards ${ }^{\mathrm{e}}$, Gero Kurat ${ }^{\mathrm{a}}$, Gordon R. Osinski ${ }^{\mathrm{f}}$, Judith M. Pillinger ${ }^{\mathrm{d}}$, \\ Claude-Alain Roten ${ }^{\mathrm{g}}$, Suzy Sancisi-Frey ${ }^{\mathrm{d}}$ \\ ${ }^{a}$ Naturhistorisches Museum, Burgring 7, 1010 Wien, Austria \\ ${ }^{\mathrm{b}}$ Centre de Biophysique Moléculaire, rue Charles Sadron, 45071 Orléans cedex 2, France \\ ${ }^{\mathrm{c}}$ European Space and Technology Centre (ESTEC), Keplerlaan 1, Postbus 299, 2200 AG Noordwijk, The Netherlands \\ ${ }^{\mathrm{d}}$ Planetary and Space Sciences Research Institute, Centre for Earth, Planetary Space and Astronomical Research, Open University, Milton Keynes, UK \\ ${ }^{\mathrm{e}}$ Chemical and Forensic Sciences, School of Life Sciences, University of Bradford, Bradford BD7 1DP, UK \\ ${ }^{\mathrm{f}}$ Canadian Space Agency, St.-Hubert, Que., Canada \\ ${ }^{\mathrm{g}}$ Institut de Génétique et de Biologie Microbiennes, Faculté de Médecine, 19 rue César Roux, CH-1005 Lausanne, Switzerland
}

Received 23 March 2007; received in revised form 28 December 2007; accepted 29 December 2007

Available online 4 January 2008

\begin{abstract}
The generic concept of the artificial meteorite experiment STONE is to fix rock samples bearing microorganisms on the heat shield of a recoverable space capsule and to study their modifications during atmospheric re-entry. The STONE-5 experiment was performed mainly to answer astrobiological questions. The rock samples mounted on the heat shield were used (i) as a carrier for microorganisms and (ii) as internal control to verify whether physical conditions during atmospheric re-entry were comparable to those experienced by "real" meteorites. Samples of dolerite (an igneous rock), sandstone (a sedimentary rock), and gneiss impactite from Haughton Crater carrying endolithic cyanobacteria were fixed to the heat shield of the unmanned recoverable capsule FOTON-M2. Holes drilled on the back side of each rock sample were loaded with bacterial and fungal spores and with dried vegetative cryptoendoliths. The front of the gneissic sample was also soaked with cryptoendoliths.

The mineralogical differences between pre- and post-flight samples are detailed. Despite intense ablation resulting in deeply eroded samples, all rocks in part survived atmospheric re-entry. Temperatures attained during re-entry were high enough to melt dolerite, silica, and the gneiss impactite sample. The formation of fusion crusts in STONE-5 was a real novelty and strengthens the link with real meteorites. The exposed part of the dolerite is covered by a fusion crust consisting of silicate glass formed from the rock sample with an admixture of holder material (silica). Compositionally, the fusion crust varies from silica-rich areas (undissolved silica fibres of the holder material) to areas whose composition is "basaltic". Likewise, the fusion crust on the exposed gneiss surface was formed from gneiss with an admixture of holder material. The corresponding composition of the fusion crust varies from silica-rich areas to areas with "gneiss" composition (main component potassium-rich feldspar). The sandstone sample was retrieved intact and did not develop a fusion crust. Thermal decomposition of the calcite matrix followed by disintegration and liberation of the silicate grains prevented the formation of a melt.

Furthermore, the non-exposed surface of all samples experienced strong thermal alterations. Hot gases released during ablation pervaded the empty space between sample and sample holder leading to intense local heating. The intense heating below the protective sample holder led to surface melting of the dolerite rock and to the formation of calcium-silicate rims on quartz grains in the sandstone sample.
\end{abstract}

(C) 2008 Elsevier Ltd. All rights reserved.

Keywords: Artificial meteorite; Atmospheric entry; Dolerite; Sandstone; Gneiss impactite; Fusion crust

\footnotetext{
${ }^{*}$ Corresponding author. Tel.: + 43152177270 ; fax: + 43152177264 .

E-mail address: franz.brandstaetter@nhm-wien.ac.at (F. Brandstätter).
} 


\section{Introduction}

The basic concept of the artificial meteorite experiment STONE is to fix rock samples on the heat shield of a recoverable space capsule and to study their modifications during atmospheric re-entry. The first experiment STONE1 was performed in 1999 in order to address the question whether Martian meteoroids of sedimentary origin could survive atmospheric entry and thus could fall as "Martian" meteorites on Earth (Brack et al., 2002). Unfortunately, the succeeding experiments STONE-2 to STONE-4 were not successful for several reasons. STONE-2 samples were lost because of crash landing of the capsule, STONE-3 was never launched, and STONE-4 samples were lost due to explosion of the carrier rocket immediately after launch.

The STONE-5 experiment was performed mainly with astrobiological questions. The rock samples mounted on the capsule's heat shield were used (i) as a carrier for microorganisms and (ii) as internal control to verify whether physical conditions during atmospheric re-entry were comparable to those experienced by "real" meteorites. Samples of dolerite (an igneous rock), sandstone (a sedimentary rock), and gneiss impactite from Haughton carrying endolithic cyanobacteria were fixed to the heat shield of the unmanned recoverable capsule FOTON-M2. Holes drilled on the back side of each rock sample were loaded with bacterial (Bacillus subtilis) and fungal (Ulocladium atrum) spores and with dried vegetative cyanobacterium (Chroococcidiopsis sp.). The front of the gneissic rock was also soaked with Chroococcidiopsis sp. to simulate a natural endolithic community. Biological investigation of the gneiss impact sample showed that the heat of entry ablated and heated the original rock to a temperature well above the upper temperature limit for life to below the depth at which light levels are insufficient for photosynthetic organisms $(\sim 5 \mathrm{~mm})$, thus killing all of its photosynthetic inhabitants. This study showed that atmospheric transit acts as a strong biogeographical dispersal filter to the interplanetary transfer of photosynthesis (Cockell et al., 2007).

Here we report on the results of the mineralogical investigations of the STONE-5 experiment based on the observed differences between pre- and post-flight samples. Special attention was dedicated to the fusion crust as a potential protective barrier for the microorganisms and as a specific mineralogical marker of the stone. The generation of significant fusion crusts in STONE-5 was a real novelty since they did not form in STONE-1, thus strengthening the link with real meteorites. For STONE-1 different sample materials were used including a basalt, which unfortunately was lost before the landing of the capsule.

Although the re-entry speed of $7.7 \mathrm{~km} / \mathrm{s}$ of the capsule was considerably lower than the $12-20 \mathrm{~km} / \mathrm{s}$ of typical meteoroids it was expected that frictional heat would be sufficient to form fusion crusts on the surfaces of samples. For re-entry speeds in the range of natural meteoroids one might expect higher peak temperatures and faster ablation rates during atmospheric passage. However, if formation of fusion crust on the samples occurs, thermal conditions during the experiment should be comparable to those experienced by meteoroids, although the peak temperatures attained by the latter were not reached.

\section{Samples and flight details}

Three samples were selected for the STONE-5 experiment:

(1) A dolerite (coarse-grained basaltic rock from Pauliberg, Burgenland, Austria) of Miocene age (Poultidis and Scharbert, 1986). Major mineral phases of the dolerite (Fig. 1) are $\sim 3 \mathrm{~mm}$ to $<1 \mathrm{~cm}$-sized crystals of pyroxene (augite) and feldspar (plagioclase). Opaque phases are dominated by $\mathrm{Fe}-\mathrm{Ti}$ oxides (ilmenite and magnetite). The dolerite has a texture similar to that of extraterrestrial basalts (eucrites and shergottites) and was chosen to serve as an in-flight control and to demonstrate that the frictional heat was sufficient to form a fusion crust during re-entry.

The modal composition (in vol\%) of dolerite from the Pauliberg location (Piso, 1970) is $4.4 \%$ olivine, $19.5 \%$ augite, $45 \%$ plagioclase, $13.2 \%$ alkali-feldspar, $13 \%$ opaques, $3.9 \%$ apatite, $1.0 \%$ biotite. The corresponding chemical analysis (in $\mathrm{wt}^{2} \%$ ) is given as $50.2 \% \mathrm{SiO}_{2}, 3.9 \%$ $\mathrm{TiO}_{2}, 18.5 \% \mathrm{Al}_{2} \mathrm{O}_{3}, 4.0 \% \mathrm{Fe}_{2} \mathrm{O}_{3}, 2.5 \% \mathrm{FeO}, 0.15 \% \mathrm{MnO}$, $4.2 \% \mathrm{MgO}, 8.9 \% \mathrm{CaO}, 3.7 \% \mathrm{Na}_{2} \mathrm{O}, 2.6 \% \quad \mathrm{~K}_{2} \mathrm{O}, 0.43 \%$ $\mathrm{P}_{2} \mathrm{O}_{5}, 0.45 \% \mathrm{H}_{2} \mathrm{O}^{+}$, and $0.38 \% \mathrm{H}_{2} \mathrm{O}^{-}$.

(2) A sedimentary rock (sandstone) from Wallsee, Lower Austria, Austria. The sandstone at Wallsee comprises the major part of the Upper Oligocene Molasse zone which is overlain by a thin layer (locally 3-5 m thickness) of glacial sediments. The basement of the sandstone is formed by granites of the Bohemian Massif (Schnabel, 2002). The sandstone consists mainly of sub-rounded to rounded

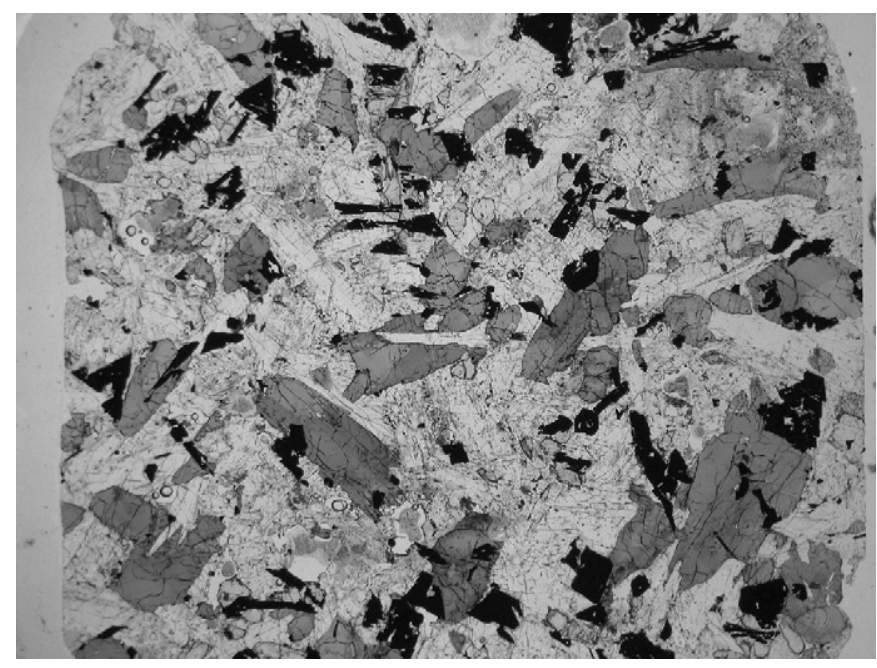

Fig. 1. Photomicrograph of the dolerite sample from Pauliberg, Burgenland, Austria, exhibiting a coarse-grained texture with crystals of augite (medium grey), feldspar (light grey), and $\mathrm{Fe}-\mathrm{Ti}$ oxides (black). Width of image $=2 \mathrm{~cm}$. 


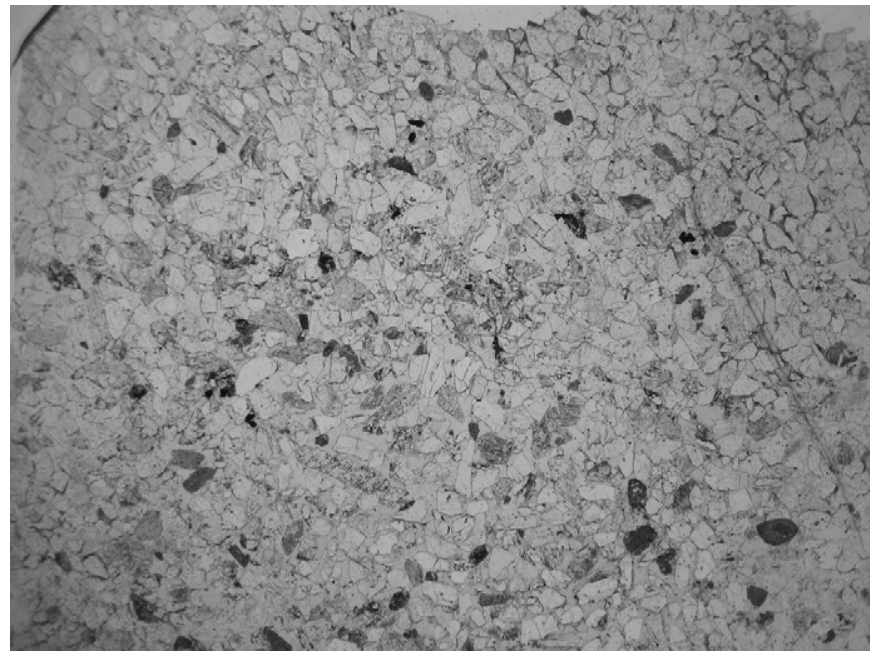

Fig. 2. Photomicrograph of the sandstone sample from Wallsee, Lower Austria, Austria, exhibiting sub-rounded to rounded grains of quartz and alkali-feldspar set in a matrix of calcite. Width of image $=2 \mathrm{~cm}$.

grains $(<1 \mathrm{~mm}$ to several $\mathrm{mm}$ in size) of quartz and alkalifeldspar set in a matrix of calcite (Fig. 2). Its modal composition (in vol\%) was calculated from digitally processed SEM images to $45 \%$ calcite, $41 \%$ quartz, and $14 \%$ alkali-feldspar. This rock was selected to address the possibility for sedimentary rocks to survive terrestrial atmospheric entry in analogy to the dolostone sample used in the STONE-1 experiment (Brack et al., 2002).

(3) An impactite (shocked gneiss) from the Haughton impact crater, Devon Island, Canada, formed about $39 \mathrm{Ma}$ ago (Metzler et al., 1988; Osinski et al., 2005). This rock was chosen because it naturally hosts cryptoendolithic organisms (Cockell et al., 2002) and is an approximation to the type of shocked fractured habitat that might be found on planetary bodies. The gneiss which has been strongly altered by the impact event exhibits a very porous texture (Fig. 3) and can be described as consisting of three main constituents: (i) diaplectic quartz $(\sim 60 \mathrm{vol} \%)$, (ii) bubblerich glass $(\sim 15-20 \mathrm{vol} \%)$, and (iii) pore space $(\sim 20 \mathrm{vol} \%)$. In places, remnants of crystalline quartz are present (confirmed by powder XRD analysis). The bubble-rich glass (compositional range $\sim 6.4-10 \mathrm{wt} \% \mathrm{~K}_{2} \mathrm{O}, 22-25 \mathrm{wt} \%$ $\mathrm{Al}_{2} \mathrm{O}_{3}, 64-67 \mathrm{wt} \% \mathrm{SiO}_{2}$ ), which very likely represents molten potassium feldspar, is partly altered to illite.

The rock samples were shaped into disks of $7 \mathrm{~cm}$ diameter (of which the central $5 \mathrm{~cm}$ was exposed), $1 \mathrm{~cm}$ thick, and fixed to the surface of the ablative heat shield of the Foton-M2 capsule. Sample holders (Fig. 4) consisting of an annular disk of material similar to that of the heat shield (glass textolite, i.e. a glass fabric material impregnated with a phenol-formaldehyde resin) were used to clamp the samples around the stagnation point of the capsule. The sample holders were secured in place by bolts; no bonding adhesive was used.

Foton-M2 was launched on 31 May 2005 at Baikonur (Kazakhstan) and landed on 16 June south of Kostanay (Kazakhstan). Flight duration was 15.8 days. The Foton

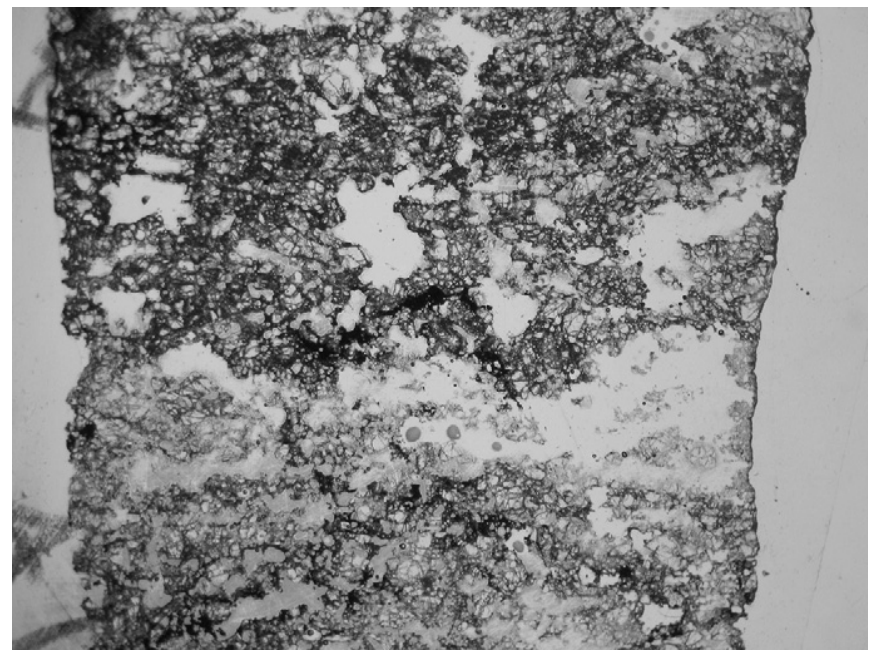

Fig. 3. Photomicrograph of the impactite (gneiss) sample from the Haughton impact crater, Devon Island, Canada, a strongly shocked rock exhibiting a foamy, highly porous texture. Width of image $=2 \mathrm{~cm}$.

\section{exposed side}

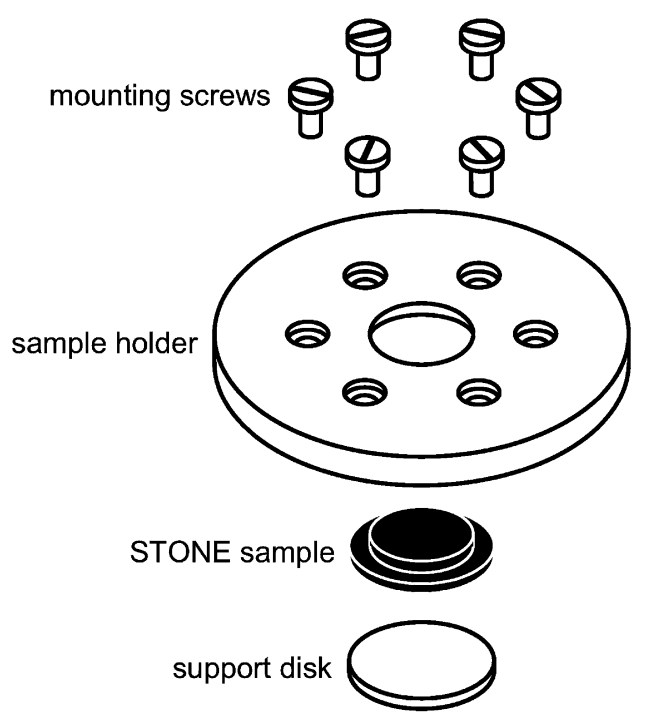

Fig. 4. STONE-5 sample holder. The sample holder $(20 \mathrm{~cm}$ in diameter $)$, the mounting screws and the support disk $(7 \mathrm{~cm}$ in diameter) were made of the same material as that of the heat shield (glass textolite, i.e. a glass fabric material impregnated with a phenol-formaldehyde resin).

spacecraft orbits the Earth at a speed of $7.7 \mathrm{~km} / \mathrm{s}$. The orbital shape is near-circular, with a perigee of $262.5 \mathrm{~km}$ and an apogee of $312.5 \mathrm{~km}$. Each orbital loop is completed in $90.0 \mathrm{~min}$, which makes exactly 16 orbits per day. Deorbiting is triggered by the ignition of a retro-rocket whereby the velocity is reduced to $7.6 \mathrm{~km} / \mathrm{s}$. By this seemingly modest deceleration, the orbital trajectory is altered in such a way that it intersects the surface of the Earth. Thus, when the retro-rocket has been fired, the satellite is destined to hit the ground. The retro-rocket of Foton-M2 was fired over the coast of Namibia at an 
altitude of $275 \mathrm{~km}$. During atmospheric entry the capsule was travelling almost parallel to the surface of the Earth. The landing parachute was deployed 24 min later at an altitude $9 \mathrm{~km}$ over Kazakhstan, some $10.000 \mathrm{~km}$ away. The heating history of the STONE samples was confined to the last few minutes of that $24 \mathrm{~min}$ period, when the denser layers of the atmosphere were crossed. The estimated maximum heating rate was between 600 and $1100 \mathrm{~kW} / \mathrm{m}^{2}$. Heating was over when the capsule, decelerated by air drag, was being cooled by the atmosphere.

The re-entry capsule of the Foton spacecraft is a spherical $2.2 \mathrm{~m}$ diameter structure, massing around $2500 \mathrm{~kg}$. Being ball-shaped, there is no morphological nose or tail. By design, the centre of mass is not positioned in the middle. By this off-set, the capsule enters into the atmosphere with a pre-defined part of its surface in front, in ram direction. The rocks from the STONE experiment were fitted into that area.

\section{Sample handling and experimental methods}

At the landing site it turned out that after the capsule touched down all samples (except the dolerite) remained intact on the heat shield without apparent contamination. The dolerite which was fallen off lay on the ground close to the capsule. Therefore, a soil sample was taken from that spot for identification of possible soil-borne contamination. All samples were removed with glove-covered hands, mounted on an acryl plate and sealed into sterilized plastic bags. After delivering the samples to ESTEC at Noordwijk, The Netherlands, they were first taken to research laboratories in Great Britain and Switzerland for biological investigations. Finally, the remaining sample material was sent to the Natural History Museum in Vienna.

For mineralogical investigations, polished thin sections of the pre-flight and post-flight samples were prepared. For the post-flight samples at first slabs were made by dry cutting along a line on the holder disk. The set of cut slabs was then used for thin section preparation. All samples were investigated by optical microscopy and analytical scanning electron microscopy using a JEOL JSM 6400 SEM (operating conditions $15 \mathrm{kV}$ acceleration potential and $\sim 1-2 \mathrm{nA}$ sample current). Chemical analyses were performed using a KEVEX SuperDry $\mathrm{Si}(\mathrm{Li})$ detector linked to a VANTAGE EDS system. Detection limit for the analysed elements is $0.3-0.5 \mathrm{wt} \%$. The analytical error (3 Sigma) based on counting statistics is given together with the analyses in the tables.

\section{Results and discussion}

All sample descriptions in this paragraph refer to the returned samples (consisting of the sample holder, the rock sample, and the support disk) as they arrived at the Natural History Museum, Vienna.

\subsection{Dolerite}

A macroscopic inspection of the sample holder plus post-flight sample already revealed that the dolerite sample had formed a fusion crust during atmospheric re-entry. This crust consists of black to brownish-black melt (Figs. 5a and b) extending from the exposed part of the dolerite sample to the periphery of the sample holder. Because of its colour and surface morphology, the dolerite melt can easily be distinguished from the molten heat shield material (Fig. 5a) that apparently continuously was flowing over the sample holder and the dolerite. A cross-section perpendicular to the sample surface revealed that the fusion crust consists of a bubble-rich glass. In transmitted light the glass appears brownish with a marked rhythmic change in colour intensity and exhibits deformation
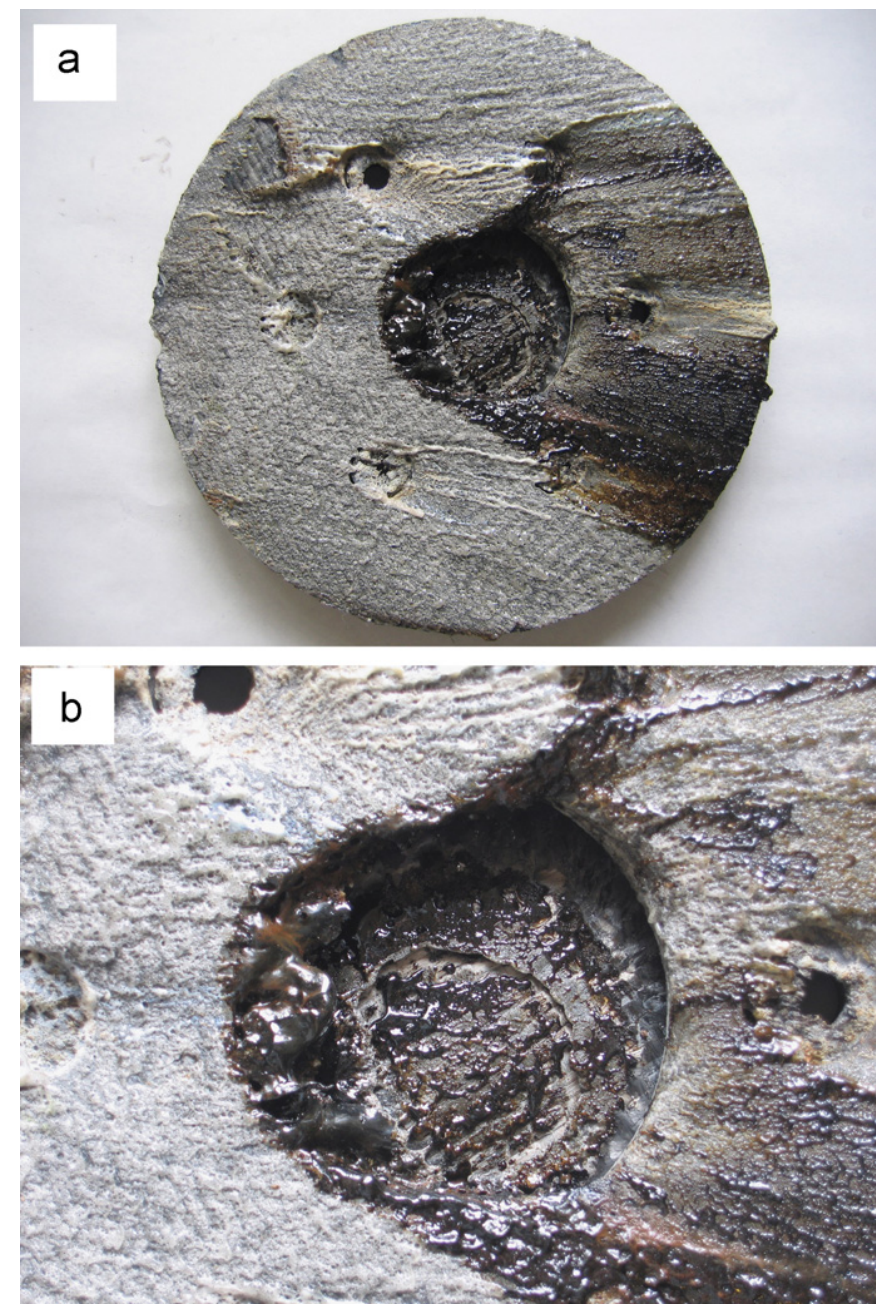

Fig. 5. (a) Front side of sample holder with exposed surface of the postflight dolerite sample. A black to brownish-black melt is distributed on one side of the holder disk in a radiating manner. The black melt (flowing from left to right) extends from the exposed part of the dolerite sample to the periphery of the sample holder. In addition, the surface of the sample holder is covered by a white to grey coloured melt consisting of molten heat shield material. (b) Detail of the exposed part (diameter $=5 \mathrm{~cm}$ ) of the deeply eroded dolerite sample exhibiting a shiny black to brownish black glass consisting mainly of molten dolerite. 
Table 1

Selected EDS-analyses from different areas of the post-flight dolerite sample [in wt $\%$, recalculated to total $=100 \%$ after deduction of concentrations below detection limit (b.d.), statistical error $(3 \sigma)$ in units of the last digit in parentheses]

\begin{tabular}{|c|c|c|c|c|c|c|c|c|c|c|}
\hline \multirow[t]{2}{*}{ Area } & \multicolumn{4}{|l|}{ BSE 1} & \multicolumn{3}{|l|}{ BSE 2} & \multicolumn{3}{|l|}{ BSE $3 / 1$} \\
\hline & $\# 1$ & $\# 2$ & $\# 3$ & $\# 4$ & $\# 1$ & $\# 2$ & $\# 3$ & $\# 1$ & $\# 3$ & $\# 4$ \\
\hline $\mathrm{SiO}_{2}$ & 92.2 (14) & $81.8(12)$ & $62.8(12)$ & $53.1(10)$ & 94.3 (13) & 52.7 (11) & $49.0(10)$ & $52.7(10)$ & $59.2(12)$ & $67.6(12)$ \\
\hline $\mathrm{TiO}_{2}$ & b.d. & b.d. & $2.5(03)$ & $4.4(05)$ & b.d. & $5.0(05)$ & $5.2(05)$ & $8.0(06)$ & $6.5(05)$ & b.d. \\
\hline $\mathrm{Al}_{2} \mathrm{O}_{3}$ & $4.9(03)$ & $8.4(04)$ & $16.3(06)$ & $14.9(06)$ & $5.0(03)$ & $11.8(05)$ & $11.8(05)$ & $14.4(06)$ & $15.7(06)$ & $20.9(06)$ \\
\hline $\mathrm{FeO}$ & b.d. & b.d. & $5.5(05)$ & $9.4(07)$ & b.d. & $10.2(07)$ & $11.0(06)$ & $5.7(06)$ & $3.5(05)$ & b.d. \\
\hline $\mathrm{MgO}$ & $1.6(03)$ & $7.2(03)$ & $3.1(03)$ & $6.6(04)$ & b.d. & $7.4(04)$ & $9.1(04)$ & $7.3(04)$ & $4.1(04)$ & b.d. \\
\hline $\mathrm{CaO}$ & b.d. & b.d. & $5.2(03)$ & $7.3(04)$ & b.d. & $9.6(04)$ & $10.7(05)$ & $8.3(04)$ & $6.4(04)$ & b.d. \\
\hline $\mathrm{K}_{2} \mathrm{O}$ & $1.2(02)$ & b.d. & $2.0(02)$ & $1.2(02)$ & $0.7(01)$ & $1.0(02)$ & $0.7(02)$ & $0.7(02)$ & $1.7(02)$ & $7.5(03)$ \\
\hline $\mathrm{Na}_{2} \mathrm{O}$ & b.d. & $2.5(02)$ & $2.5(03)$ & $3.0(03)$ & b.d. & $2.2(03)$ & $2.4(03)$ & $2.8(03)$ & $2.8(03)$ & $4.0(03)$ \\
\hline
\end{tabular}

BSE 1: fusion crust; BSE 2: contact sample holder-fusion crust; BSE 3: non-exposed sample surface.

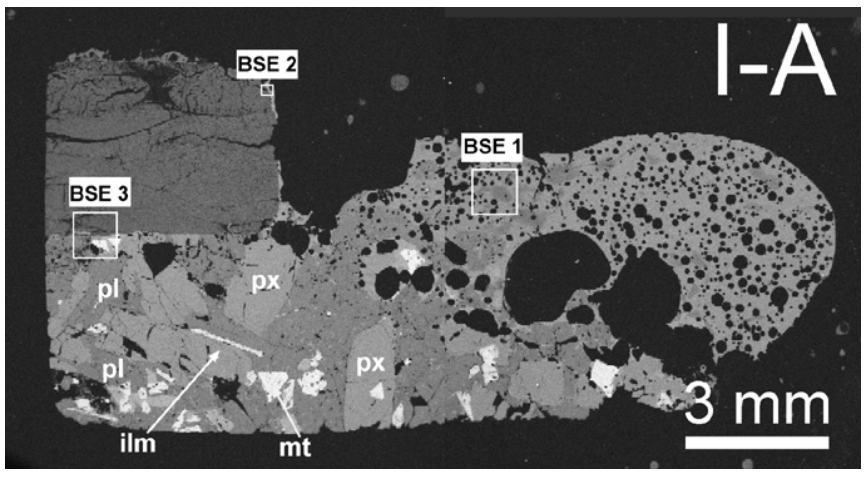

Fig. 6. SEM image (BSE mode) of a cross-section through the post-flight dolerite sample showing the exposed sample surface and part of the sample holder. The exposed dolerite is covered mainly by fusion crust containing numerous bubbles of different sizes whereas the non-exposed sample exhibits the coarse-grained dolerite texture. Areas selected for quantitative SEM analysis are indicated by squares. BSE 1 = fusion crust; BSE $2=$ contact sample holder - fusion crust; BSE $3=$ non-exposed sample surface; $\quad \mathrm{ilm}=$ ilmenite; $\mathrm{mt}=$ magnetite, $\mathrm{pl}=$ plagioclase; px $=$ pyroxene.

features due to glass flow before solidification. The presence of numerous bubbles indicates intense de-gassing of the fusion crust during its formation.

SEM-EDS-analyses (Table 1) made at different locations within the sample (Figs. 6 and 7) revealed that all areas of its surface were strongly affected by heating. The fusion crust has a highly variable chemical composition ranging from silica-rich $\left(>90 \mathrm{wt} \% \mathrm{SiO}_{2}\right)$ to areas having approximately basaltic composition. In places, remnants of apparently undissolved silica fibres from the heat shield material can be recognized "floating" in the fusion crust (Fig. 7a). However, the contact between sample holder and fusion crust appears mainly compact and well defined without a diffuse contact zone (Fig. 7b). Fusion of dolerite also took place at the non-exposed sample surface covered by the sample holder (Fig. 7c). Melting below the sample holder indicates heating by hot gases that pervaded mainly along the interface between sample holder and the nonexposed dolerite surface. Interestingly, the fusion crust formed on the non-exposed sample (Fig. 7d) is decorated by tiny $(<1-5 \mu \mathrm{m}$ sized) magnetite crystals. The same feature can be observed in completely molten dolerite fragments (Fig. 7d) with magnetite crystals concentrated on the surface of these objects. Magnetite crystals of comparable sizes are known to occur as accessory phases at and in the fusion crust of micrometeorites and stony meteorites (Kurat et al., 1994; Genge and Grady, 1999).

\subsection{Sandstone}

In places on the sample holder and most of the exposed sample were covered by a thin white to grey coloured melt which most likely consisted entirely of molten heat shield material. However, the post-flight sample available for mineralogical investigations consisted of a light beige coloured rock without any macroscopic visible fusion crust. When the very friable sample arrived at the NHMV, about half of it had disintegrated into sand. For this study only the non-disintegrated part was used.

Optical microscopy also revealed that the post-flight sample lacked any glassy material that could be related to the melting of sandstone. Nevertheless, an intense thermal alteration of the exposed sample was indicated by darkening of the calcium carbonate (calcite) matrix. SEM investigation of different areas within the sandstone (Fig. 8) showed that the exposed as well as the non-exposed surface was strongly modified (Fig. 9). In places calcite from the outer part located close to the sample surface was decomposed into $\mu \mathrm{m}$-sized sub-grains resulting in a mottled appearance (Fig. 10a). The corresponding different shades of grey in BSE images indicate inhomogeneous decomposition and/or subsequent terrestrial alteration on a $\mu \mathrm{m}$ sized scale. In contrast, calcite from the interior part exhibits a non-altered smooth surface (Fig. 10b). In addition, strong thermal alterations at the non-exposed sample surface below the sample holder are indicated by the presence of quartz grains rimmed by a Ca-silicate seam (Figs. 9c and d). Quantitative EDS-analysis of the 

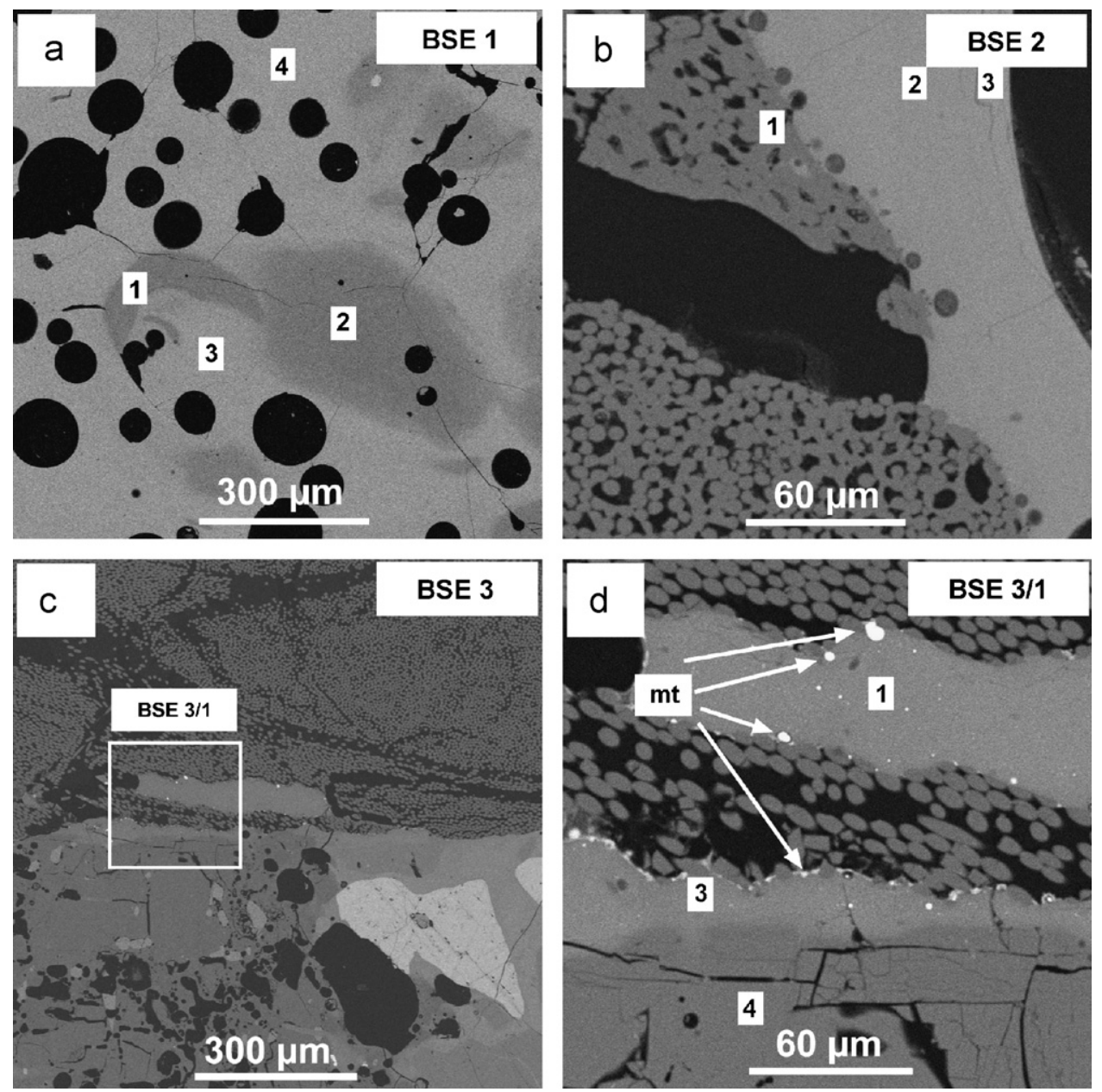

Fig. 7. SEM images (BSE mode) from different locations within the dolerite sample. Numbers on the images correspond to positions of analyses as listed in Table 1. (a) BSE 1 from the fusion crust of the dolerite sample exhibiting remnants of undissolved silica fibres (grey) in glass (white). (b) BSE 2 from the contact sample holder-fusion crust. Silica fibres (dark grey) and glass (light grey) form a compact intergrowth with a well-defined, non-porous boundary. In places (upper-left) the silica fibres stick together to form larger aggregates. (c) BSE 3 from the non-exposed sample surface beneath the sample holder. An elongated glass (centre of image) fragment was incorporated into the heat shield material. (d) Detail of image BSE 3. The presence of glass (\#1 and \#3) on the surface of the non-exposed sample indicates that temperatures below the sample holder were high enough to melt the dolerite. Noteworthy, the surface of the glass is decorated by tiny magnetite $(\mathrm{mt})$ crystals - a feature observed in the fusion crust of some stony meteorites.

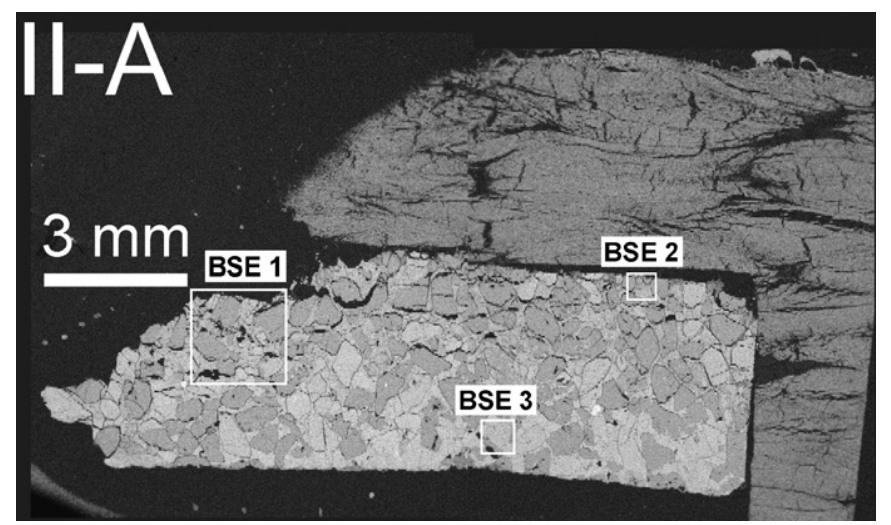

Fig. 8. SEM image (BSE mode) of a cross-section through the post-flight sandstone sample showing the exposed sample surface and part of the sample holder. Selected areas from the SEM study are indicated by squares. BSE $1=$ exposed sample surface; BSE $2=$ non-exposed sample surface; BSE $3=$ interior part of the sample.
$\mathrm{Ca}$-silicate revealed that the atomic ratio of $\mathrm{Ca}: \mathrm{Si}$ is close to 2:1. A possible mechanism for the growth of Ca-silicate on quartz could be either the in situ formation via reaction of quartz with the adjacent calcite matrix or via reaction with $\mathrm{CaO}$-bearing species mobilized by hot gases.

The lack of a fusion crust on the sandstone can in principle be explained by comparing its calcium carbonate matrix with the post-flight dolostone from the STONE-1 experiment. For the latter it was argued (Brack et al., 2002) that the lack of fusion crust can be attributed to (i) the highly refractive nature of the solid oxides $\mathrm{CaO}$ and $\mathrm{MgO}$ formed by thermal decomposition of the dolomite (melting temperatures $>2800^{\circ} \mathrm{C}$ ), (ii) the physical weakness of the oxide mixture, and (iii) the chemical instability of $\mathrm{CaO}$ in the terrestrial atmosphere. Thus, it is very likely that the calcite cement of the sandstone disintegrated thermally into $\mathrm{CaO}$ (solid) and $\mathrm{CO}_{2}$ during the atmospheric entry. 

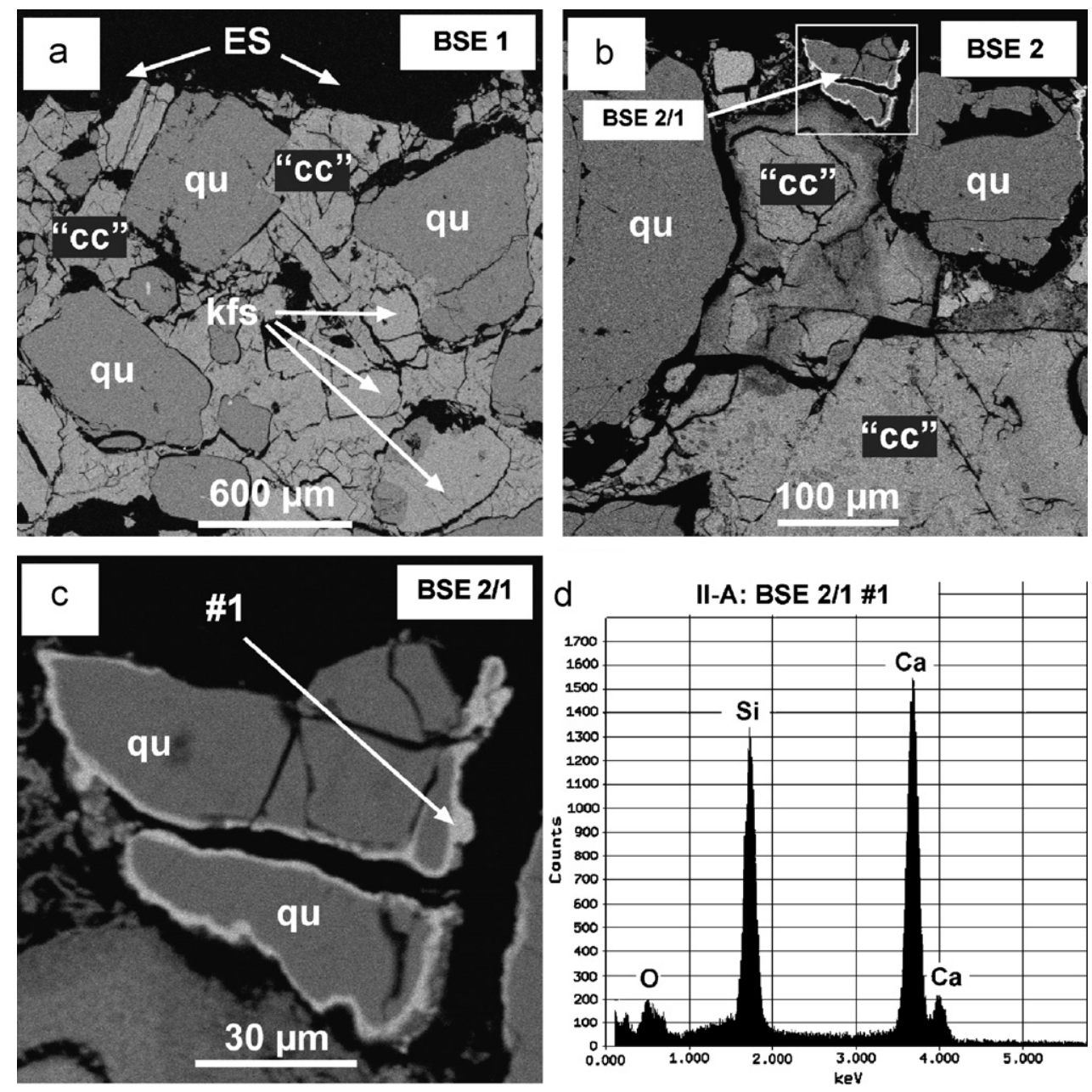

Fig. 9. SEM images (BSE mode) from different locations within the sandstone sample. (a) BSE 1 located near the exposed surface (ES). Grains of quartz (qu) and K-feldspar ( $\mathrm{kfs}$ ) are set in a calcium carbonate matrix (calcite). In places the calcite exhibits a mottled appearance (denoted by "cc") indicating intense thermal alteration. (b) BSE 2 from the non-exposed sample surface below the sample holder. The presence of quartz grains rimmed by a Ca-silicate seam (area BSE 2/1) and partly decomposed calcium carbonate indicate intense heating and thermal alteration including gaseous species. (c) Detail of image BSE 2 exhibiting a reaction rim consisting of Ca-silicate on the surface of quartz grains. (d) Typical EDS-spectrum of the Ca-silicate rim around the quartz grains shown in Fig. 8c. A quantitative EDS-analysis (point \#1) revealed that the atomic ratio $\mathrm{Ca} / \mathrm{Si}$ is close to 2.
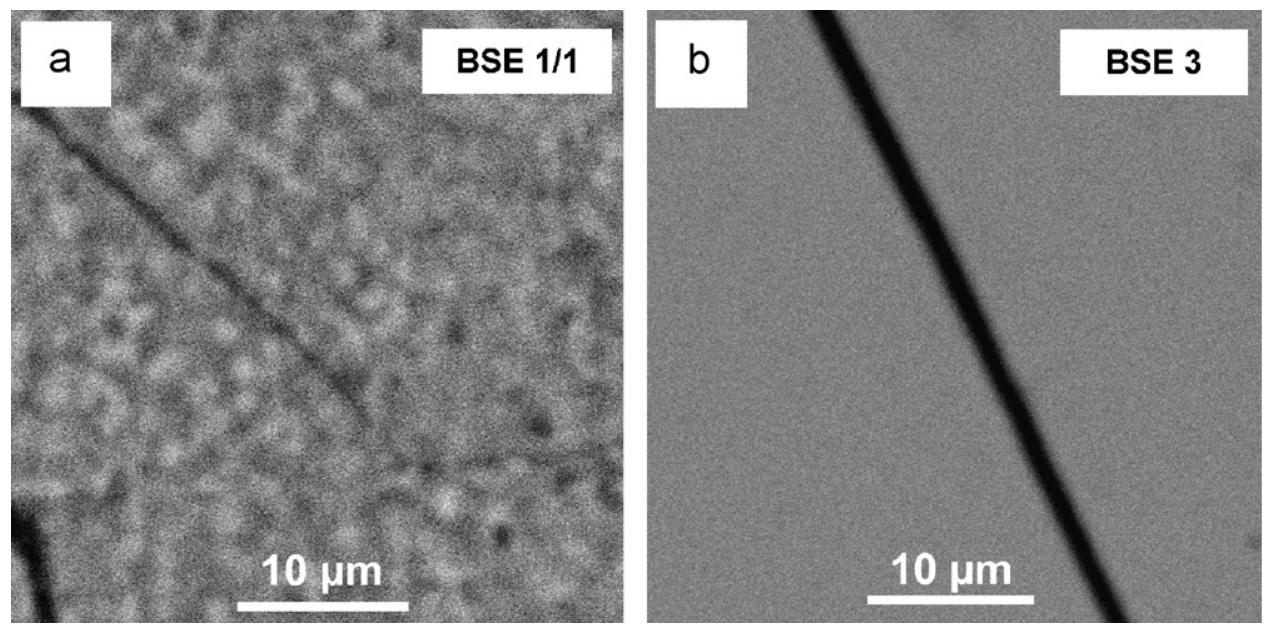

Fig. 10. SEM images (BSE mode) of the calcite matrix from two different locations within the sandstone sample. (a) Strongly altered calcite from the outer part located close to the exposed surface. Intense thermal alteration apparently led to decomposition into $\mu \mathrm{m}$-sized sub-grains resulting in a mottled appearance. (b) Calcite from the interior part exhibiting a non-altered smooth surface. 
Because of the carbonate decomposition, grains of feldspar and quartz were liberated and mechanically removed before melting of the silicates could take place.

\subsection{Impactite (shocked gneiss)}

Similar to the dolerite a macroscopic inspection of the post-flight sample already revealed that the gneiss sample had formed a fusion crust during atmospheric re-entry. This crust consists of a whitish melt concentrated on one side of the deeply eroded sample. The molten gneiss forms thick "droplets" which are distinct from the rather greyish melt of the holder material. The exposed sample surface and part of the sample holder are almost entirely covered by melt. The extent of melting and thermal alteration of the gneiss sample was apparently enforced by the porous texture of the pre-flight rock sample (Fig. 11). Hot gases released during the ablation of both the sample and the sample holder could pervade the porous sample interior. Thus, the transport of additional heat to the sample's interior increased the intensity of thermal alteration of the gneiss.

Bulk EDS-analyses (Fig. 12, Table 2) revealed that the melt formed on the exposed sample surface consists of molten gneiss (main component K-rich feldspar) with variable admixtures of holder material. The chemical composition of the melt, which apparently was flowing from the sample over the holder (areas \#4 and \#5 on Fig. 12), is very close to that of the heat shield material.

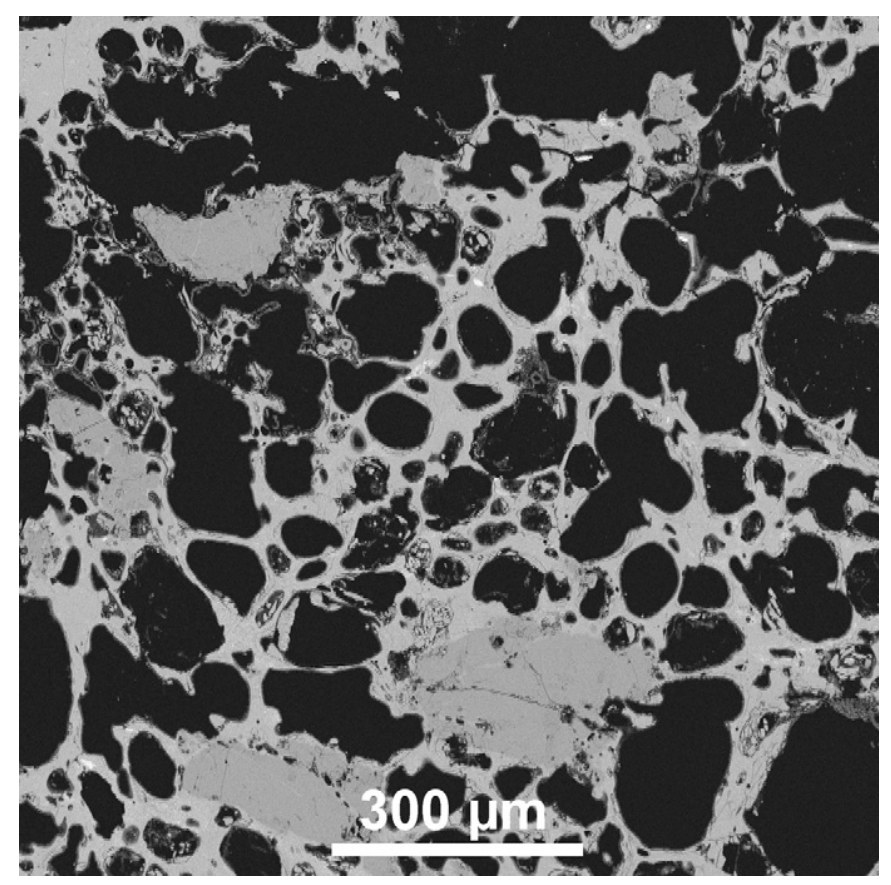

Fig. 11. SEM image (BSE mode) exhibiting the in places porous texture of the pre-flight impactite (gneiss) sample. Bubble-rich glass (light grey) that apparently formed during the impact event was mainly transformed to phyllosilicates.

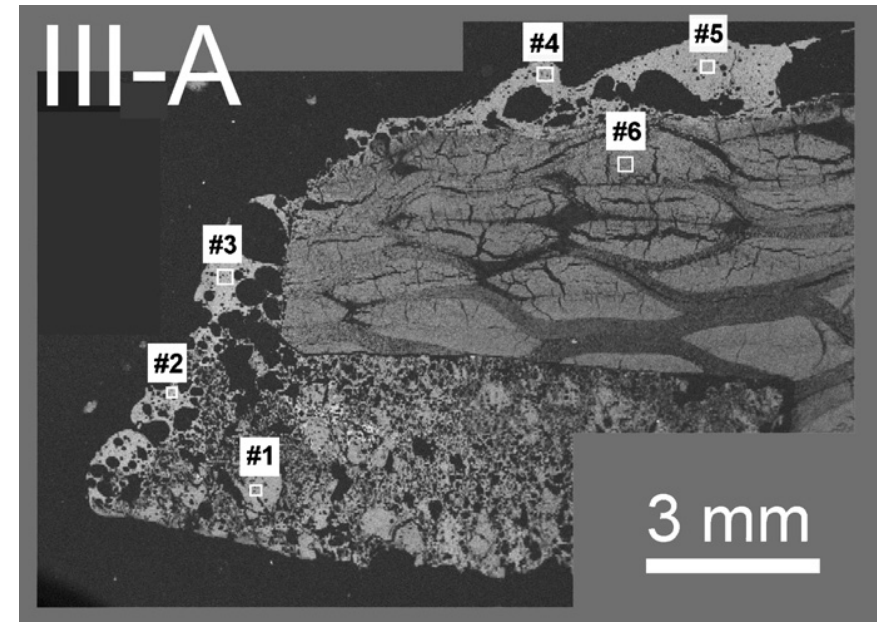

Fig. 12. SEM image (BSE mode) of a cross-section through the post-flight impactite (gneiss) sample. EDS-bulk analyses of selected areas (marked by squares) are listed in Table 2 (\#1 = sample interior; \#2 to \#5= fusion crust; $\# 6$ = sample holder).

Table 2

Selected EDS-analyses from different areas of the post-flight gneiss sample [in $\mathrm{wt} \%$, recalculated to total $=100 \%$ after deduction of concentrations below detection limit (b.d.), statistical error $(3 \sigma)$ in units of the last digit in parentheses]

\begin{tabular}{|c|c|c|c|c|c|c|}
\hline Area & \#1 & \#2 & \#3 & \#4 & \#5 & \#6 \\
\hline $\mathrm{SiO}_{2}$ & 86.7 (13) & $78.3(12)$ & 97.9 (13) & $92.5(13)$ & 92.1 (13) & $95.1(15)$ \\
\hline $\mathrm{Al}_{2} \mathrm{O}_{3}$ & $9.1(04)$ & $14.7(05)$ & $2.1(03)$ & $6.8(03)$ & $7.2(03)$ & $4.9(04)$ \\
\hline $\mathrm{K}_{2} \mathrm{O}$ & $3.6(02)$ & $5.2(03)$ & b.d. & $0.7(01)$ & $0.7(01)$ & b.d. \\
\hline $\mathrm{Na}_{2} \mathrm{O}$ & $0.7(02)$ & $1.8(03)$ & b.d. & b.d. & b.d. & b.d. \\
\hline
\end{tabular}

All analyses are bulk measurements of the areas marked in Fig. 12. Area \#6 is located in the sample holder (heat shield material).

\section{Conclusion}

The exposed part of the dolerite is covered by a fusion crust consisting of silicate glass formed from the rock sample with an admixture of holder material (silica). Compositionally, the fusion crust varies from silica-rich areas (undissolved silica fibres of the holder material) to areas whose composition is "basaltic". Likewise, the fusion crust on the exposed gneiss surface was formed from gneiss with an admixture of holder material. The corresponding composition of the fusion crust varies from silica-rich areas to areas with "gneiss" composition (main component potassium-rich feldspar). The sandstone sample did not develop a fusion crust. Thermal decomposition of the calcite matrix followed by disintegration and liberation of the silicate grains prevented the formation of a melt.

The non-exposed surface of all samples experienced also strong thermal alterations. Hot gases released during ablation pervaded the empty space between sample and sample holder leading to intense local heating. The intense heating below the protective sample holder led to surface 
melting of the dolerite rock and to the formation of calcium-silicate rims on quartz grains in the sandstone sample.

Despite intense ablation resulting in deeply eroded samples all rocks in part survived atmospheric re-entry. Temperatures attained during re-entry were high enough to melt dolerite, silica and the gneiss sample.

\section{Acknowledgements}

The flight opportunity for STONE-5 on Foton-M2 was provided by ESA (the European Space Agency). The experiment was supported by CNES. F.B. thanks the Oskar und Friederike Ermann-Fonds for financial support. We thank Robert Seemann for collecting the sandstone samples and Georg Sverak for petrographic sample preparation.

\section{References}

Brack, A., Baglioni, P., Bourrat, G., Brandstätter, F., Demets, R., Edwards, H.G.M., Genge, M., Kurat, G., Miller, M.F., Newton, E.M., Pillinger, C.T., Roten, C.A., Wäsch, E., 2002. Do meteoroids of sedimentary origin survive terrestrial atmospheric entry? The ESA artificial meteorite experiment STONE. Planet. Space Sci. 50, 763-772.

Cockell, C.S., Lee, P., Osinski, G., Horneck, G., Broady, P., 2002. Impactinduced microbial endolithic habitats. Meteorit. Planet. Sci. 37, 1287-1298.
Cockell, C.S., Brack, A., Wynn-Williams, D.D., Baglioni, P., Brandstätter, F., Demets, R., Edwards, H., Gronstal, A., Kurat, G., Lee, P., Osinski, G.R., Pearce D., Pillinger, J., Roten, C.A., Sancisi-Frey, S., 2007. Interplanetary transfer of photosynthesis: an experimental demonstration of a selective dispersal filter in planetary island biogeography. Astrobiology 7 (1), 1-9.

Genge, M.J., Grady, M.M., 1999. The fusion crusts of stony meteorites: implications for the atmospheric reprocessing of extraterrestrial materials. Meteorit. Planet. Sci. 34, 341-356.

Kurat, G., Koeberl, C., Presper, T., Brandstätter, F., Maurette, M., 1994 Petrology and geochemistry of Antarctic micrometeorites. Geochim. Cosmochim. Acta 58, 3879-3904.

Metzler, A., Ostertag, R., Redeker, H.-J., Stöffler, D., 1988. Composition of the crystalline basement and shock metamorphism of crystalline and sedimentary target rocks at the Haughton impact crater, Devon Island, Canada. Meteoritics 23, 197-203.

Osinski, G.R., Lee, P., Spray, J.G., Parnell, J., Lim, D.S.S., Bunch, D.E., Cockell, C.S., Glass, B., 2005. Geological overview and cratering model for the Haughton impact structure, Devon Island, Canadian High Arctic. Meteorit. Planet. Sci. 40, 1759-1776.

Piso, E., 1970. Zusammensetzung und Genese der Basalte des Pauliberges und von Stoob-Oberpullendorf (Burgenland). Tschermaks Miner. Petr. Mitt. 14 (3), 103-139.

Poultidis, H., Scharbert, H.G., 1986. Bericht über geochemisch-petrologische Untersuchungen an basaltischen Gesteinen des österreichischen Teils der transdanubischen vulkanischen Region. Anz. Österr. Akad. Wiss., Math.-Naturwiss. K1. 123, 65-76.

Schnabel, W., 2002. Geologische Karte von Niederösterreich 1:200.000. Legende und Kurzerläuterungen. 1-47. Geologische Bundesanstalt, Wien. 